\title{
Thrombosis of a Superior Mesenteric Vein Aneurysm: Transarterial Thrombolysis and Transhepatic Aspiration Thrombectomy
}

\author{
Hechelhammer, L ; Crook, D W ; Widmer, U ; Wildermuth, S ; Pfammatter, T
}

\begin{abstract}
We report the case of a 31-year-old woman presenting with abdominal pain due to acute thrombosis of a superior and inferior mesenteric vein aneurysm, which was treated by a combination of arterial thrombolysis and transhepatic thrombus aspiration. At the last follow-up CT, 21 months following this procedure, there was no evidence of rethrombosis, and the patient continues to do well under oral anticoagulation. The literature regarding these uncommon mesenteric vein aneurysms without portal vein involvement, as well as their treatment options, is reviewed
\end{abstract}

DOI: https://doi.org/10.1007/s00270-004-0020-x

Posted at the Zurich Open Repository and Archive, University of Zurich

ZORA URL: https://doi.org/10.5167/uzh-155836

Journal Article

Published Version

Originally published at:

Hechelhammer, L; Crook, D W; Widmer, U; Wildermuth, S; Pfammatter, T (2004). Thrombosis of a Superior Mesenteric Vein Aneurysm: Transarterial Thrombolysis and Transhepatic Aspiration Thrombectomy. Cardiovascular and Interventional Radiology, 27(5):551-555.

DOI: https://doi.org/10.1007/s00270-004-0020-x 


\title{
Thrombosis of a Superior Mesenteric Vein Aneurysm: Transarterial Thrombolysis and Transhepatic Aspiration Thrombectomy
}

\author{
L. Hechelhammer, ${ }^{1}$ D.W. Crook, ${ }^{1}$ U. Widmer, ${ }^{2}$ S. Wildermuth, ${ }^{1}$ T. Pfammatter ${ }^{1}$ \\ ${ }^{1}$ Institute of Diagnostic Radiology, University Hospital of Zürich, Rämistrasse 100, 8091 Zürich, Switzerland \\ ${ }^{2}$ Department of Medicine, University Hospital of Zürich, Zürich, Switzerland
}

\begin{abstract}
We report the case of a 31-year-old woman presenting with abdominal pain due to acute thrombosis of a superior and inferior mesenteric vein aneurysm, which was treated by a combination of arterial thrombolysis and transhepatic thrombus aspiration. At the last follow-up CT, 21 months following this procedure, there was no evidence of rethrombosis, and the patient continues to do well under oral anticoagulation. The literature regarding these uncommon mesenteric vein aneurysms without portal vein involvement, as well as their treatment options, is reviewed.
\end{abstract}

Key words: Mesenteric vein aneurysm-Thrombolysis-Thrombosis-Transhepatic thrombus aspiration

In the past, visceral venous aneurysms were considered an exceedingly rare pathology. Nowadays, they are more often diagnosed due to the widespread utilization of the different cross-sectional abdominal imaging modalities in the investigation of abdominal disorders. In 2002, Lau et al. reported 42 cases of extrahepatic portal vein aneurysms, seven of them published before 1980 [1]. Superior mesenteric vein aneurysms without portal involvement are even more infrequent. A review of the English literature revealed 10 published cases of a superior but none of an inferior mesenteric vein aneurysm (Table 1) [2-12].

Possible complications of portal venous system aneurysms include thrombosis, rupture or pressure effects on adjacent visceral organs [13-15]. Acute thrombosis can result in life-threatening portal hypertension with rupture of the aneurysm, gastrointestinal bleeding or bowel infarction $[13,16]$. Depending on the extent of the thrombosis, different therapeutic options are possible: surgical or percutaneous thrombectomy $[17,18]$, systemic anticoagulation [19] or local thrombolysis [20-22].

We describe a case of an acute superior and inferior mesenteric vein aneurysm thrombosis with successful revascularization by transarterial thrombolysis and transhepatic thrombus aspiration in a patient with multiple abdominal vein aneurysms of unknown origin.

\section{Case Report}

A 31-year-old woman with a 10-day history of increasing diffuse abdominal pain and associated nausea was diagnosed in another hospital to have a superior and inferior mesenteric venous aneurysm $(35 \mathrm{~mm}$ and $23 \mathrm{~mm}$

Correspondence to: T. Pfammatter, M.D.; email: thomas.pfammatter@usz.ch diameter, respectively) thrombosis at computed tomography (CT). The portal vein was occluded up to its bifurcation, but of normal caliber (Fig. 1). In addition, aneurysmal dilatation of the inferior vena cava $(55 \mathrm{~mm})$, the hemiazygos vein $(16 \mathrm{~mm})$, the right ovarian $(32 \mathrm{~mm})$ and the right iliacal internal vein $(25 \mathrm{~mm})$ was noted. At CT imaging, there were no signs of bowel ischemia or ascites. Two years prior to this admission, the patient had suffered from an episode of multiple segmental and subsegmental postoperative pulmonary emboli after excision of a flank lipoma. The subsequent laboratory screening for possible causes of venous thrombosis was negative. The Caucasian patient had previously given birth to four healthy children without any problems. There was no family history of thrombosis.

At our institution indirect portography via the celiac and superior mesenteric artery showed occlusion of the superior and inferior mesenteric vein without any collateral venous drainage, indicating acute thrombosis. Transfemorally placed angiographic endhole catheters (Cobra, 4 Fr; Cordis, Miami Lakes, FL) were left in the superior mesenteric and splenic arteries for urokinase infusion (50,000 units/hr each, 7.2 million units total dose). Additionally intravenous heparinization with 20,000 units/24 hr was started. Fourty-eight hours later, repeated indirect portography showed no significant changes. Therefore, percutaneous transhepatic portal access was gained via the right midaxillary line (Neff-set, Cook, Bloomington, IL). A 9 Fr, $23-\mathrm{cm}$-long sheath was introduced. The soft clot was easily traversed by a guidewire. Direct portography demonstrated occlusion of the inferior and superior mesenteric vein (Fig. 2A), extending to the right branch of the main portal vein. However, the intrahepatic portal vein branches were patent. Mechanical thrombectomy was attempted first with a pigtail fragmentation catheter, originally designed to dissolve acute pulmonary emboli (SchmitzRode catheter; Cook, Bloomington, IL). As this maneuver was unsuccessful, the rotation catheter was exchanged for an angled 9 Fr guiding catheter (Cordis, Miami Lakes, FL) in order to aspirate the clot with a $60 \mathrm{ml}$ syringe without a valve. Approximately 1 liter of fresh, red thrombotic material and blood was suctioned in about 15 passes. During this procedure several peripheral intrahepatic portal vein branches were occluded by flushed thrombotic material. Therefore, pharmacologic local thrombolysis was restarted via single catheters placed in the superior mesenteric vein (pigtail catheter, $5 \mathrm{Fr}$ ) and the superior mesenteric artery (50,000 units of urokinase per hour per catheter over $24 \mathrm{hr}$; total of 2.4 million units).

The following day, direct portography showed complete recanalization of the superior mesenteric vein aneurysm and the intrahepatic portal venous branches (Fig. 2B). The portal venous pressure was normal (12 mmHg). The inferior mesenteric vein remained occluded. The patient's symptoms resolved completely. The procedure was terminated by embolization of the transhepatic access route with Gianturco coils (4 mm diameter, Cook, Bloomington, IL), followed by gelatin sponge plugs. Full heparin anticoagulation was resumed the same day.

The following day, documentary CT showed residual partial thrombosis of the distal splenic vein and a completely thrombosed aneurysmatic inferior mesenteric vein (23 mm maximal diameter) in an otherwise fully patent 
Table 1. Cases of mesenteric vein aneurysm in the English literature

\begin{tabular}{|c|c|c|c|c|c|c|c|}
\hline Year & Author & $\begin{array}{l}\text { Reference } \\
\text { no. }\end{array}$ & Location & Thrombosis & Therapy & Clinical symptoms & $\begin{array}{l}\text { Transverse } \\
\text { diameter } \\
(\mathrm{mm})\end{array}$ \\
\hline 1982 & Schild & {$[2]$} & SMV & None & No treatment given & $\begin{array}{l}\text { Loss of appetite and weight, } \\
\text { abdominal pain }\end{array}$ & 40 \\
\hline 1985 & $\begin{array}{l}\text { Lopez- } \\
\text { Rasines }\end{array}$ & {$[3]$} & SMV & $\begin{array}{l}\text { Small white thrombus } \\
\text { probable }\end{array}$ & No treatment given & Abdominal pain & $\begin{array}{l}\text { Not } \\
\text { mentioned }\end{array}$ \\
\hline 1985 & Cholankeril & [4] & $\begin{array}{l}\text { SMV and confluence } \\
\text { with SV }\end{array}$ & None & $\begin{array}{l}\text { Transarterial } \\
\text { vasopressin } \\
\text { injection }\end{array}$ & $\begin{array}{l}\text { Hematemesis due to portal } \\
\text { hypertension and } \\
\text { esophageal varices }\end{array}$ & $\begin{array}{l}\text { Not } \\
\text { mentioned }\end{array}$ \\
\hline 1986 & Crolla & {$[5]$} & SMV & None & No treatment given & $\begin{array}{l}\text { Abdominal pain and } \\
\text { hematuria by } \\
\text { sonographically proven } \\
\text { nephrolithiasis }\end{array}$ & 35 \\
\hline 1987 & Mathias & [6] & SMV & None & Resection & Abdominal pain & 50 \\
\hline 1987 & Wise & [7] & SMV & Complete & Resection & $\begin{array}{l}\text { Abdominal pain and } \\
\text { vomiting }\end{array}$ & 50 \\
\hline 1993 & Sedat & {$[8]$} & $\begin{array}{l}\text { SMV and confluence } \\
\text { with SV }\end{array}$ & None & No treatment given & Asymptomatic & 60 \\
\hline 1996 & Lerch & {$[9]$} & SMV & None & Resection & Asymptomatic & 30 \\
\hline 1996 & Fulcher & {$[10]$} & SMV & None & No treatment given & $\begin{array}{l}\text { Abdominal pain, nausea and } \\
\text { vomiting }\end{array}$ & 18 \\
\hline 1999 & Özbek & {$[12]$} & $\begin{array}{l}\text { SMV and confluence } \\
\text { with SV }\end{array}$ & None & No treatment given & Asymptomatic & 20 \\
\hline
\end{tabular}

SMV, superior mesenteric vein; SV, splenic vein
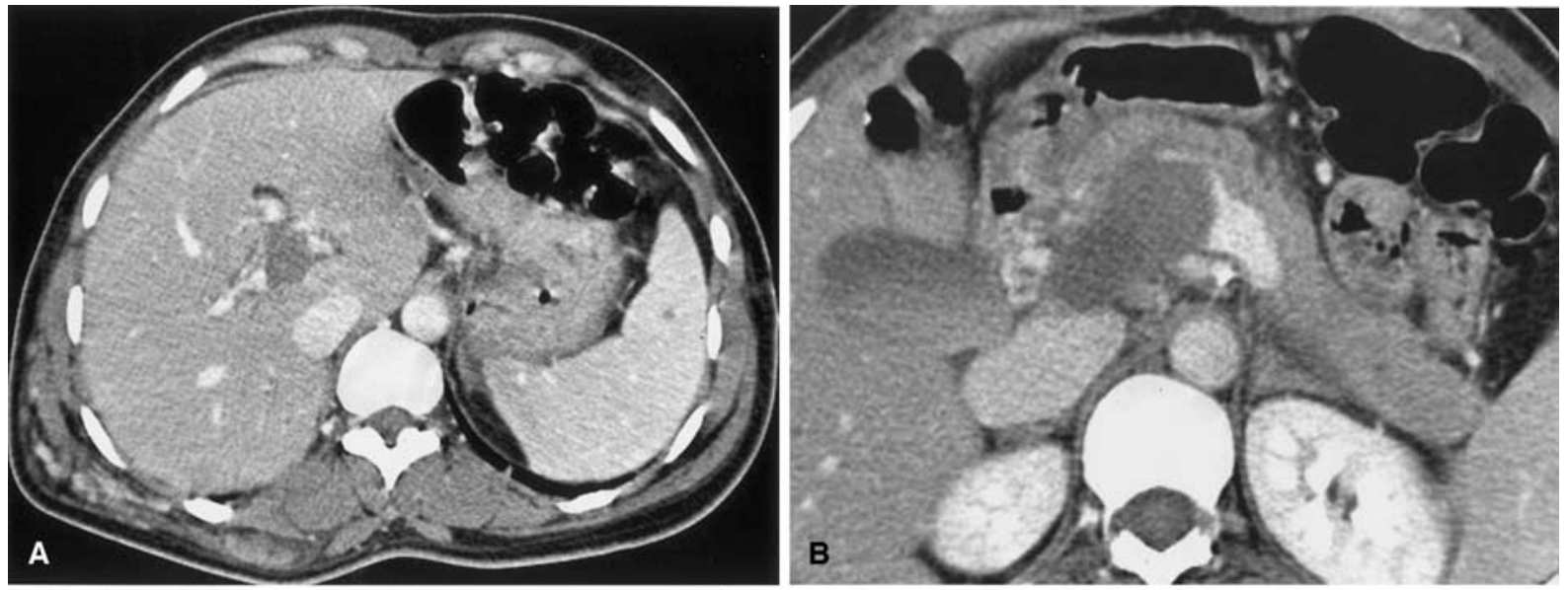

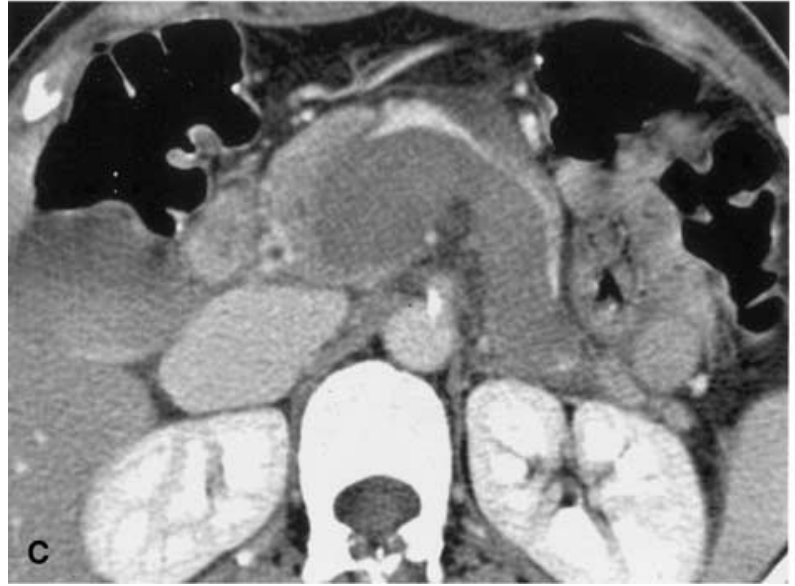

Fig. 1. Transverse $C T$ scans showing occlusion of the portal vein bifurcation (A), the confluence sinus (B), and the aneurysmatic superior and inferior mesenteric vein (C). Multiplanar reconstruction
(MPR) of the abdominal CT showing the thrombosed superior mesenteric and portal vein (D). 

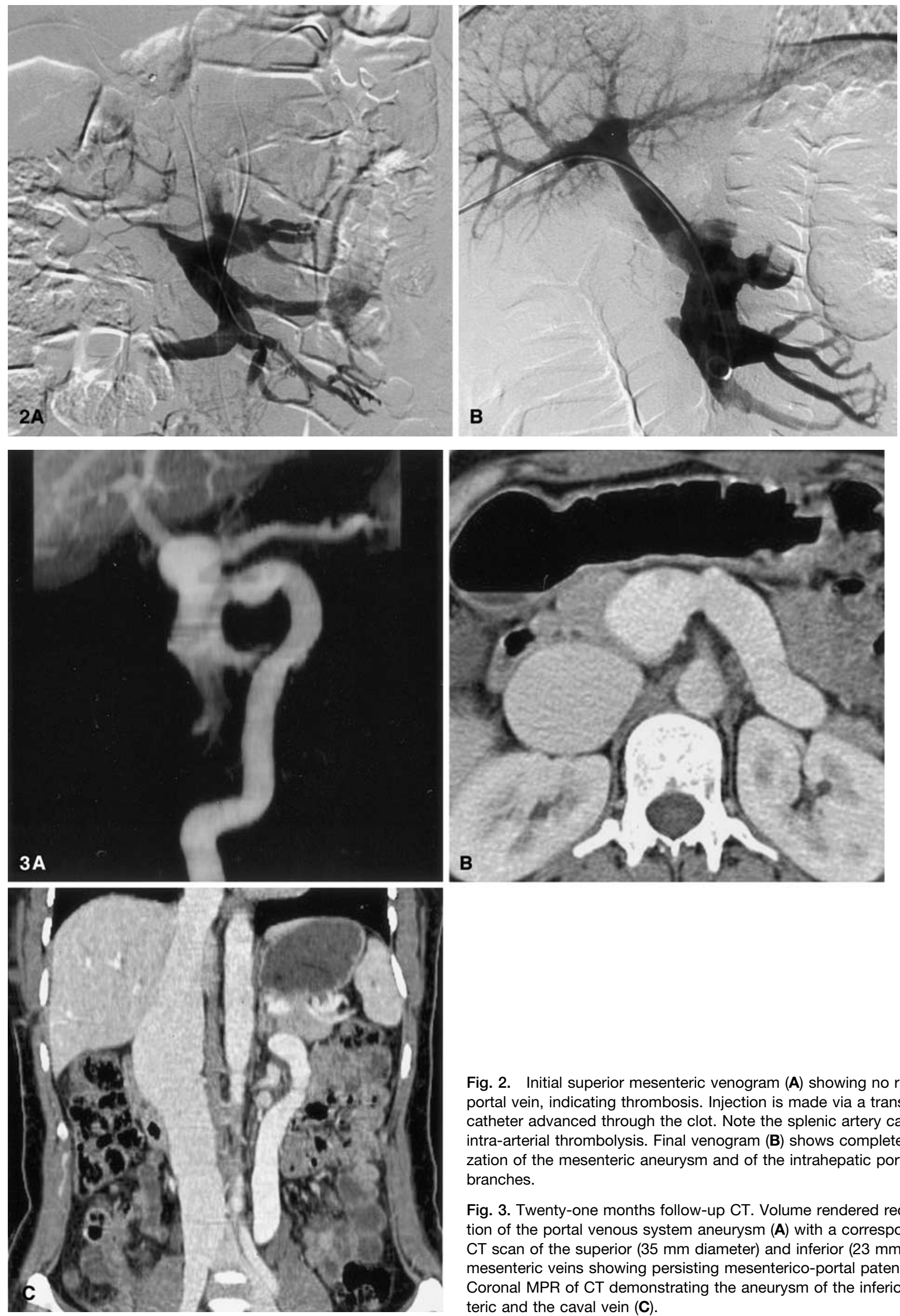

Fig. 2. Initial superior mesenteric venogram (A) showing no runoff in the portal vein, indicating thrombosis. Injection is made via a transhepatic catheter advanced through the clot. Note the splenic artery catheter for intra-arterial thrombolysis. Final venogram (B) shows complete recanalization of the mesenteric aneurysm and of the intrahepatic portal venous branches.

Fig. 3. Twenty-one months follow-up CT. Volume rendered reconstruction of the portal venous system aneurysm (A) with a corresponding axial CT scan of the superior ( $35 \mathrm{~mm}$ diameter) and inferior (23 $\mathrm{mm}$ diameter) mesenteric veins showing persisting mesenterico-portal patency (B). Coronal MPR of CT demonstrating the aneurysm of the inferior mesenteric and the caval vein (C). 
portal venous system. Six days later, the patient suffered a new episode of nonspecific abdominal pain. The abdominal CT showed a subcapsular liver hematoma in the previous transhepatic access site. Heparin was stopped. To rule out a treatable cause of the hematoma, a hepatic arteriogram and a splenoportography were performed. As neither showed any abnormalities and there was no laboratory or hemodynamic evidence of a persisting hemorrhage, heparin anticoagulation was resumed after 5 days.

Three days later the patient once again experienced an episode of diffuse abdominal pain. This time abdominal CT revealed thrombosis of the previously patent but aneurysmatic right ovarian vein extending into the inferior caval vein. Activated prothrombin time was $91 \mathrm{sec}$. Overlapping oral anticoagulation with phenprocoumon was started with a high-intensity dosage (INR 3.0 or more), and the patient was discharged after 44 days of hospitalization with no other medication. No new thrombotic events have been noted since.

Follow-up CT at 5 and 21 months showed patency of the portal venous system but unchanged size of the aneurysms of the inferior caval (Fig. 3B, C), hemiazygos, right ilical internal and superior (Fig. 3A, B) and inferior mesenteric veins (Fig. 3). Thus, the latter had recanalized spontaneously. The right ovarian vein was chronically thrombosed.

Hematologic investigation, which was repeated 1 year after the acute event, again did not reveal any abnormalities. Lifelong continuation of oral anticoagulation was recommended to the patient in view of the venous stasis in the aneurysmatic vessels as a persisting thromboembolic risk factor.

\section{Discussion}

Portal venous system aneurysms can be defined as a dilatation of more than $2 \mathrm{~cm}$ [23]. Congenital and acquired causes for these aneurysms have been discussed. An acquired origin is postulated in cases with portal hypertension or a history of necrotizing pancreatitis $[10,14]$. Conversely, the in utero diagnosis of a portal vein aneurysm [24] as well as the prevalence of portal vein aneurysms in livers without any sign of portal hypertension [25] support a congenital origin. Failed prenatal regression of the right primitive vitelline vein or inherent weakness of the vein wall are proposed etiologies in these patients $[14,26]$. In our patient we assumed a congenital origin in view of the normal portal venous pressure and history lacking necrotizing pancreatitis, abdominal trauma or surgery. As the venomegaly was affecting the systemic as well as the portal abdominal circulation, we postulate an inborn weakness of the venous vessel walls in our patient.

Including our case, a total of 11 cases of isolated aneurysms of the mesenteric vein (without portal vein involvement) have been reported in the English literature to date (Table 1). Their maximal diameter ranged from 18 to $60 \mathrm{~mm}$. Except for two patients, they were all women, aged between 37 and 60 years. Three of these aneurysms were asymptomatic and incidentally detected at abdominal imaging. Seven of the described aneurysms presented clinically with severe abdominal pain. Just one mesenteric vein aneurysm was associated with upper gastrointestinal hemorrhage due to esophageal varices, suggesting its association with long-standing portal hypertension. Acute thrombosis of a mesenteric vein aneurysm, as occurred in our patient, has been previously described in just one patient, who was treated by resection [7]. Considering the possible recanalization of the small capillaries and venules in addition to the main veins as well as the lesser degree of invasiveness, transarterial thrombolysis has been proposed as an alternative to surgical procedures for acute mesenterico-portal thrombosis [20, 27]. Obviously, evidence of bowel infarction may direct the patient toward surgical or interventional treatment. Furthermore, outcome comparison between a surgical and an interventional approach seems unfair as mortality of acute mesenterico-portal thrombosis is determined by the associated bowel necrosis [17]. In our case there was no clinical or radiological evidence of bowel infarction and, due to their multiplicity, surgical correction of the abdominal vein aneurysms was not feasible.

Likely due to the large clot burden in the aneurysmatic superior mesenteric vein and the portal vein, transarterial thrombolysis via the superior mesenteric and splenic artery was ineffective in our patient. Therefore, additional mechanical declotting was performed. Usually, percutaneous access to the portal system is gained via either a transjugular or a direct transhepatic approach [18, 28]. Transjugular portal access is advantageous, in particular, if there is associated intrahepatic portal hypertension, as portal outflow can be improved by simultaneous creation of an intrahepatic portosystemic shunt (TIPS). On the other hand, device maneuverability is limited, making access to thrombosed intrahepatic portal branches difficult or impossible, and there is an increased risk of periprocedural pulmonary embolization with the transjugular access after TIPS creation. As there was no evidence of liver cirrhosis or a coagulation disorder, we favored the direct transhepatic route in our patient. After failed clot fragmentation with a rotational pigtail catheter, surprisingly, simple aspiration thrombectomy was efficacious and associated with little intrahepatic portal thromboembolization. A drawback of both the transjugular and direct transhepatic methods is the higher risk of bleeding at either the puncture or the track site, especially in those patients requiring local thrombolysis and eventually systemic anticoagulation. However, the risk of an intraperitoneal hemorrhage is likely higher with the large-bore direct transhepatic access compared with the transjugular portal access. Indeed, in spite of portal vein access via a small peripheral branch and postinterventional embolization of the tract, a delayed subcapsular hepatic hemorrhage occurred while the patient was fully anticoagulated. This complication of direct transhepatic mesenterico-portal aspiration thrombectomy was treated by temporary discontinuation of oral anticoagulation therapy and can therefore be considered as a major complication Class C (according to SIR, Standard of Practice Committee Classification of Complications by Outcome).

In summary, literature review suggests that mesenteric vein aneurysms without involvement of the portal vein are a rare idiopathic condition affecting mainly women. In about half of the patients they are asymptomatic. If acutely thrombosed, percutaneous treatment by a combination of transarterial thrombolysis and transhepatic aspiration thrombectomy is an alternative to surgical thrombectomy and aneurysm resection. This approach, followed by oral anticoagulant therapy, led to immediate relief of abdominal pain and prevented rethrombosis at mid-term in our reported case.

\section{References}

1. Lau H, Chew DK, Belkin M (2002) Extrahepatic portal vein aneurysm: A case report and review of the literature. Cardiovasc Surg 10:58-61

2. Schild H, Schweden F, Braun B, Lang H (1982) Aneurysm of the superior mesenteric vein. Radiology 145:641-642

3. Lopez-Rasines GJ, Alonso JR, Longo JM, Pagola MA (1985) Aneurysmal dilatation of the superior mesenteric vein: CT findings. J Comput Assist Tomogr 9:830-832

4. Cholankeril JV (1985) Superior mesenteric venous aneurysm. Am J Gastroenterol 80:624-626

5. Crolla D, Depuyt F, Bruneel M, Rutgeerts L, Van Aelst F, Vermeulen J (1986) Aneurysm of the superior mesenteric vein. J Belge Radiol 69:447-449

6. Mathias KD, Hoffmann J, Krabb HJ, Polonius MJ (1987) Aneurysm of the superior mesenteric vein. Cardiovasc Intervent Radiol 10:269-271

7. Wise RH Jr, Retterbush DW, Stanley RJ (1987) CT findings in acute thrombosis of superior mesenteric vein aneurysm. J Comput Assist Tomogr 11:172-174 
8. Sedat J, Padovani B, Chanalet S (1993) Aneurysm of the superior mesenteric vein. AJR Am J Roentgenol 161:903-904

9. Lerch R, Wolfle KD, Loeprecht H (1996) Superior mesenteric venous aneurysm. Ann Vasc Surg 10:582-588

10. Fulcher A, Turner M (1997) Aneurysms of the portal vein and superior mesenteric vein. Abdom Imaging 22:287-292

11. Atasoy KC, Fitoz S, Akyar G, Aytac S, Erden I (1998) Aneurysms of the portal venous system. Gray-scale and color Doppler ultrasonographic findings with CT and MRI correlation. Clin Imaging 22:414417

12. Ozbek SS, Killi MR, Pourbagher MA, Parildar M, Katranci N, Solak A (1999) Portal venous system aneurysms: Report of five cases. J Ultrasound Med 18:417-422; quiz 423

13. Thomas TV (1967) Aneurysm of the portal vein: Report of two cases, one resulting in thrombosis and spontaneous rupture. Surgery 61:550555

14. Lopez-Machado E, Mallorquin-Jimenez F, Medina-Benitez A, RuizCarazo E, Cubero-Garcia M (1998) Aneurysms of the portal venous system: Ultrasonography and CT findings. Eur J Radiol 26:210-214

15. Gallego C, Velasco M, Marcuello P, Tejedor D, De Campo L, Friera A (2002) Congenital and acquired anomalies of the portal venous system. Radiographics 22:141-159

16. Gertsch P, Matthews J, Lerut J, Luder P, Blumgart LH (1993) Acute thrombosis of the splanchnic veins. Arch Surg 128:341-345

17. Klempnauer J, Grothues F, Bektas H, Pichlmayr R (1997) Results of portal thrombectomy and splanchnic thrombolysis for the surgical management of acute mesentericoportal thrombosis. Br J Surg 84:129-132

18. Rosen MP, Sheiman R (2000) Transhepatic mechanical thrombectomy followed by infusion of TPA into the superior mesenteric artery to treat acute mesenteric vein thrombosis. J Vasc Interv Radiol 11:195-198

19. Matos C, Van Gansbeke D, Zalcman M, Ansay J, Delcour C, En- gelholm L, Struyven J (1986) Mesenteric vein thrombosis: Early CT and US diagnosis and conservative management. Gastrointest Radiol $11: 322-325$

20. Train JS, Ross H, Weiss JD, Feingold ML, Khoury-Yacoub A, Khoury PT (1998) Mesenteric venous thrombosis: Successful treatment by intraarterial lytic therapy. J Vasc Interv Radiol 9:461-464

21. Demertzis S, Ringe B, Gulba D, Rosenthal H, Pichlmayr R (1994) Treatment of portal vein thrombosis by thrombectomy and regional thrombolysis. Surgery 115:389-393

22. Bilbao JI, Rodriguez-Cabello J, Longo J, Zornoza G, Paramo J, Lecumberri FJ (1989) Portal thrombosis: Percutaneous transhepatic treatment with urokinase-a case report. Gastrointest Radiol 14:326-328

23. Dognini L, Carreri AL, Moscatelli G (1991) Aneurysm of the portal vein: Ultrasound and computed tomography identification. J Clin Ultrasound 19:178-182

24. Gallagher DM, Leiman S, Hux CH (1993) In utero diagnosis of a portal vein aneurysm. J Clin Ultrasound 21:147-151

25. Brock PA, Jordan PH Jr, Barth MH, Rose AG (1997) Portal vein aneurysm: A rare but important vascular condition. Surgery 121:105108

26. D'Andrea V, Malinovsky L, Cavallotti C, Bartolo M, Todini A, Malinovska V, Di Matteo G (1992) Venous wall ultrastructure in generalized venomegaly. Cor Vasa 34:265-272

27. Antoch G, Taleb N, Hansen O, Stock W (2001) Transarterial thrombolysis of portal and mesenteric vein thrombosis: A promising alternative to common therapy. Eur J Vasc Endovasc Surg 21:471-472

28. Ryu R, Lin TC, Kumpe D, Krysl J, Durham JD, Goff JS, Everson GT, Kam I, Wachs M, Russ P, Shrestha R, Trouillot TE, Bilir BM (1998) Percutaneous mesenteric venous thrombectomy and thrombolysis: Successful treatment followed by liver transplantation. Liver Transpl Surg 4:222-225 